\title{
Development of Grinding Wheels for Tools Manufacturing
}

Prof. Lukovics Imrich, MSc., Ph.D. ${ }^{l}$, Bílek Ondřej, MSc., Ph.D ${ }^{1}$, Dr. Holemý Stanislav, MSc. ${ }^{2}$ ${ }^{1}$ Department of Production Engineering, Faculty of Technology, Tomas Bata University in Zlín

${ }^{2}$ BEST-Business a.s., Vyškov, Czech Republic

This paper deals with the possibility of using sintered corundum of grinding tool parts. It assesses the impact of technological conditions on cutting forces during grinding, the tool wear and the quality of machined surfaces, provided changes in concentrations of grains in sintered corundum grinding wheel.

Keywords: Grinding, Sintered Corundum, Cutting Forces, Quality

\section{References}

[1] BARTUŠEK, T.; JERSÁK, J. Metoda MQL a její vliv na technologické parametry procesu broušení. Strojírenská technologie, 2009, roč. XIV, č. 1, s. 12-18. ISSN 1211-4162.

[2] BÍLEK, O.; LUKOVICS, I. Determination of the Residual Stress through the Thickness of Plastic and Metalic Parts. Manufacturing Technology. December 2006, VI, pp 12-16, ISSN 1213248-9.

[3] BÍLEK, O.; LUKOVICS, I.; SÁMEK, D. Experimentální modelování rychlostního broušení a brousících nástrojů. Strojirenská technologie. Prosinec 2007, XII, s. 12-17, ISSN 1211-4162.

[4] HOLEŠOVSKÝ, F. HRALA, M. Grinding of Ceramic Materials by Diamond Grinding Wheel. In: DMC 2002 Košice, SK, p.5-8. ISBN 80-7095-796-6.

[5] HOLEŠOVSKÝ, F.; NOVÁK, M. Influence of grinding on machine parts with design notches. Manufacturing Technology. December 2009, IX, pp 40-46, ISSN 1213248-9.

[6] HRALA, M.; BATAKO, A.; MORGAN, M. N. Thermal Modelling and Experiments in High Efficiency Deep Grinding. Manufacturing Technology. December 2006, VI, pp 5-12, ISSN 1213248-9.

[7] JURKO, J. Vplyv reznej rýchlosti na kvalitu povrchu. Funkčné povrchy 2002, Trenčín, GC TECH Trenčín 2002, p.68-71. ISBN 80-88914-71-X.

[8] KOCMAN, K.; PUTZOVÁ, I. The theoretical model of the evolution of the temperature fields in the components involved in the grinding process. Manufacturing Technology. October 2004, IV, pp 27-29, ISSN 1213248-9.

[9] KUNDRÁK, J.; ZEBALA, W.; BANA,V. Examination of Cutting Zone Deformation Occurring. Manufacturing Technology. 3/2003, pp 3-7. ISSN 1213248-9.

[10] LUKOVICS, I. Nanotechnologies when Grinding. Manufacturing Technology. December 2006, VI, pp 16-22, ISSN 1213248-9.

[11] LUKOVICS, I., SÝKOROVÁ, L.: Stanovení řezivosti brousících kotoučů pro vysokovýkonné broušení. In: Nástroje 99, Zlín, 1999, p. 96-102, ISBN 80-214-1426-X

[12] MÁDL, J. Environmental Problems in Cutting. Strojirenská technologie, 2003, roč. XII, č. 2, s. 28-32. ISSN 1211 4162.

[13] MAMALIS AG, KUNDRAK J, MANOLAKOS DE, GYANI, K., Markopoulos, A.: Thermal modelling of surface grinding using implicit finite element techniques, International Journal of Advanced Manufacturing Technology 21 (12): 929-934 SEP 2003

[14] MONKA, P.; MONKOVA, K.; ZAJAC, J. Multi Variant Process Plans. DAAAM International Scientific Book 2009. Vol.8. ISBN 978-3-901509-69-8. Vienna, 2009.

[15] MONKOVÁ, K.; MONKA, P. The coding of manufacturing system objects inside the new software application In: Archiwum technologii maszyn i automatyzacji, Quarterly. Poznan, Poland, ISSN 1233-9709. - Vol, 28, no. 4 (2008), p. 63-70.

[16] STANEK, M.; MANAS, M.; DRGA, T.; MANAS, D. Influence of Mold Cavity on Fluidity of Plastics. In: Manufacturing Technology - Journal of Science, Research and Production. Volume VI, December 2006, p.22-26, ISSN 1213248-9

[17] STANĚK, M.; MAŇAS, M.; MAŇAS, D. Vliv kvality povrchu rozvodných kanálů na zatékavost elastomerů. Strojírenská technologie, 2008, vol. XIII, no. 2, p. 8-13, ISSN 1211-4162. 
[18] SÝKOROVÁ, L., MALACHOVÁ, M. Analysis of Concentrated Power Action for PMMA. In.: Research Reports Advanced Machining Technology in Automotive Production, Cracow, November 2009, University of Technology, p.57-64, ISBN 978-83-7242-509-6.

Reviews:

Prof. František Holešovský, MSc., Ph.D. Assoc. Prof. Ivan Mrkvica, MSc., Ph.D. 